\title{
The currents, sea surface temperature, and salinity patterns in the Bay of Bengal
}

\author{
Nadia Amsalia ${ }^{1}$, Yudi Haditiar ${ }^{1}$, Reza Wafdan ${ }^{1}$, Muhammad Ikhwan², Makwiyah A. Chaliluddinn ${ }^{3}$, Sugianto Sugianto ${ }^{4}$, \\ and Syamsul Rizal ${ }^{1,2,5^{*}}$ \\ ${ }^{1}$ Department of Marine Sciences, Faculty of Marine and Fisheries, Universitas Syiah Kuala, Banda Aceh, 23111, Indonesia \\ ${ }^{2}$ Graduate School of Mathematics and Applied Sciences, Universitas Syiah Kuala, Banda Aceh, 23111, Indonesia \\ ${ }^{3}$ Department of Fisheries Resource Utilization, Faculty of Marine and Fisheries, Universitas Syiah Kuala, Banda Aceh, 23111, \\ Indonesia \\ ${ }^{4}$ Department of Soil Sciences, Faculty of Agriculture, Universitas Syiah Kuala, Banda Aceh, 23111, Indonesia \\ ${ }^{5}$ Research Center for Marine Sciences and Fisheries, Universitas Syiah Kuala, Banda Aceh 23111, Indonesia
}

\begin{abstract}
The Bay of Bengal is a semi-enclosed basin, with its southern side open to the Indian Ocean. Therefore, the current circulation is very influential in the condition of the ocean parameters. This study aims to examine the effect of current velocity on the distribution pattern of sea surface temperature (SST) and sea surface salinity (SSS) in February and August in 2017 in the Bay of Bengal. This study uses the results of Hybrid Coordinate Ocean Model (HYCOM) data for the main parameters, namely current, temperature and salinity which were analyzed with the calculation results of precipitation and evaporation data. The results of the data obtained in February showed the average current velocity conditions and low SST and relatively high SSS in the south. In August the average current velocity and SST is high and SSS is low. The results of the average data of low rainfall and relatively low evaporation are produced in February, the results of the average high rainfall and relatively high evaporation are produced in August. The resulting value gives the results of the relationship between current circulation and changes in parameter conditions in the waters.
\end{abstract}

\section{Introduction}

The Bay of Bengal $(\mathrm{BoB})$ is a bay in the northeastern Indian Ocean that resembles a triangle bordering Bangladesh, eastern India, and the Andaman Sea, and is located at coordinates $6^{\circ} \mathrm{N}-24^{\circ} \mathrm{N}$ and $78^{\circ} \mathrm{E}-98^{\circ} \mathrm{E}$ [1]. $\mathrm{BoB}$ is one of the world's largest bays, with a semienclosed shape. $\mathrm{BoB}$ is in the path of a tropical cyclone with a wide and shallow continental shelf. Current circulation in the northern Indian Ocean is influenced by the Indian monsoon current drift system, namely the northeast monsoon current (NMC) and southwest monsoon current (SMC). The northern boundary of the $\mathrm{BoB}$ is bounded by mainland Asia, and the ocean dynamics are dominated by monsoon winds, which are seasonal winds that periodically reverse direction. The $\mathrm{BoB}$ has a complicated water exchange mechanism because it is affected by wind variations, sea level dynamics, bathymetry, and mass distribution throughout the year. Monsoon currents reverse in April-May (NMC to SMC) and October-November (SMC to NMC) $[2,3]$.

The distribution of salinity in $\mathrm{BoB}$ is a distinct feature at a specific time in the northern Indian Ocean. $\mathrm{BoB}$ is known for its unique surface waters, which are influenced by mainland rivers that bring fresh water to the bay [4]. The distribution of salinity in BoB water mass is influenced by the waters of the Red Sea and
Persian Gulf, which have high salinity and evaporation [3].

Surface temperature in $\mathrm{BoB}$ is influenced by seasons, particularly during the monsoon season, which consists of winter (east monsoon) and summer (southwest monsoon) periods with intermonsoon (transitional) periods $[5,6]$. BoB is distinguished by the presence of cyclones, which frequently occur between April and October [7]. Due to current instability, the West Boundary Current (WBC) in BoB is characterized by eddy activity. The vortex's kinetic energy is greater than that of other oceans [8-10]. Rizal et al. [11] carried out monthly simulations in BoB using the HAMSOM model, which revealed the pattern of SST and SSS in 2007. The simulation was completed successfully by interpreting that the highest SST occurred in April and the lowest in October. The SST pattern depends on the wind vector from January to June.

Because of the unique circulation in BoB, current research is important. Salinity estimates in the bay's central region are heavily influenced by freshwater flows, seasonal currents, eddies, and vertical displacements of surface and subsurface waters $[5,12]$. The influx of abundant fresh water in the waters of $\mathrm{BoB}$ is generated by the runoff of rivers such as the Ganges, Brahmaputra, Irrawaddy, Meghna, Godavari, Mahanadi, Krishna and Cauvery [13].

\footnotetext{
${ }^{*}$ Corresponding author: srizal@unsyiah.ac.id
} 
The data and descriptions provide information on current velocity, temperature, salinity, and precipitation, as well as surface evaporation, through spatial mapping, which plays an important role in water circulation and climate, as well as the life of organisms in BoB waters. Current conditions affect the distribution of parameters in $\mathrm{BoB}$ and its relationship to evaporation and precipitation to temperature and sea surface salinity parameters. The purpose of this study is to investigate the characteristics and influence of current velocity on the salinity and temperature distribution patterns caused by circulation factors in the BoB. This detailed examination of the findings of research on the effect of sea water velocity on the distribution pattern of surface temperature and salinity in $\mathrm{BoB}$ is expected to provide research support and a better understanding, and it can be demonstrated through mapping.

\section{Materials and Methods}

The research was conducted at the Ocean Modeling Laboratory, Faculty of Marine and Fisheries, Universitas Syiah Kuala. The research began in January 2021. The research location is in BoB with a domain of $6.6^{\circ}-24.60^{\circ} \mathrm{N}$ and $78.20^{\circ}-96.70^{\circ} \mathrm{E}$. Topographic data obtained from ERDDAP data from the Shuttle Radar Topography Mission (STRM30) which is accessed on the website https://topex.ucsd.edu/WWWhtml/srtm30 plus.html and then plotted to the Matrix Laboratory (MATLAB), so that the topographic map in Fig. 1.

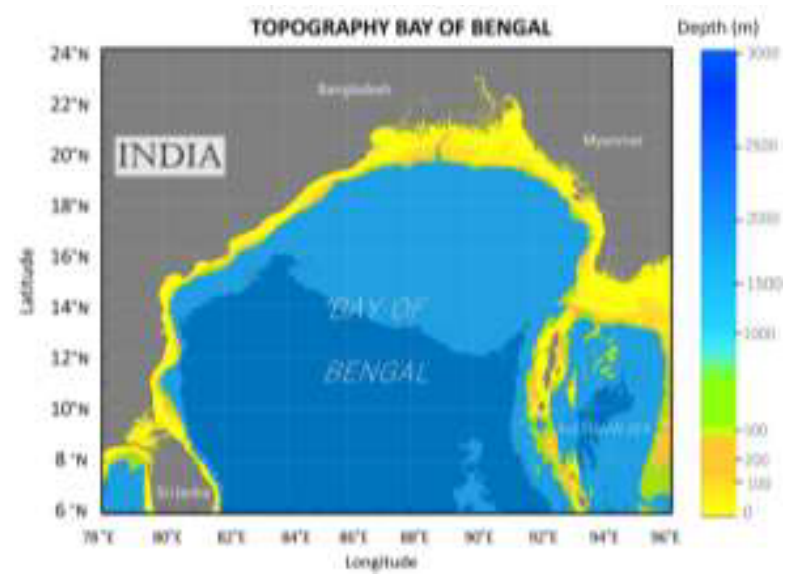

Fig. 1. BoB Topography.

\subsection{Hybrid coordinate ocean model}

Current, temperature and salinity data in the study area were obtained from the output of the Hybrid Coordinate Ocean Model (HYCOM) + NCODA Global 1/12 Reanalysis (source: https://www.hycom.org/data/ glbu0pt08/expt-91pt2). Data was extracted over a period of two months, namely February and August 2017. HYCOM + NCODA global near real time model data. This data can be used as daily data because it can be accessed within 48 hours of initial runtime. This HYCOM data has a resolution of $1 / 120 \times 1 / 120(\sim 9.25$ $\mathrm{km} \times 9.25 \mathrm{~km}$ ). Details of HYCOM data specifications in providing data in this research in Table 1 are as follows.
Table 1. HYCOM data specification.

\begin{tabular}{|c|c|}
\hline Title & HYCOM GLBu0.08 \\
\hline Resolution & $\mathbf{0 . 0 8}^{\circ}$ \\
\hline Institution & Naval Research Laboratory \\
\hline Period & $\mathbf{1 8}$ April 2016 to 20 November \\
$\mathbf{2 0 1 8}$
\end{tabular}

\subsection{Precipitation and evaporation data}

The precipitation and evaporation model data in this study were obtained from the European Center for Medium-Range Weather Forecast (ECMWF) data which was downloaded at the following link (source: https://www.ecm wf.int). The data used is daily data with units ( $\mathrm{m}$ of water equivalent) in February and August 2017 (see Table 2).

Table 2. ECMWF data specification.

\begin{tabular}{|c|c|}
\hline Title & $\begin{array}{l}\text { Eropean Centre for Medium- } \\
\text { Range Weather Forecast }\end{array}$ \\
\hline Parameter & $\begin{array}{c}\text { Total Precipitation and } \\
\text { Evaporation }\end{array}$ \\
\hline Period & January 1979 to December 2019 \\
\hline Grid & $\begin{array}{c}0.125^{\circ} \times 0.125^{\circ} \text { (ocean waves) } \\
\text { Mean }\end{array}$ \\
\hline $\begin{array}{l}\text { Temporal } \\
\text { Frequency }\end{array}$ & Daily \\
\hline
\end{tabular}

\subsection{Data Analysis}

Sea surface current data has a net common data file (NetCdf) data format obtained from HYCOM+NCODA in the form of daily data for February and August in 2017. Data extraction was carried out using MATLAB software to obtain two main current components, namely $u$ and $v$. The formula for determining the velocity of the current direction is: $\mathrm{V}=\sqrt{u^{2}+v^{2}}$. Global sea surface temperature and salinity data as well as evaporation and precipitation data are processed using MATLAB software for monthly average calculations. Image cropping is carried out according to the study area. The cropping result is exported into image formats so that it can be read and displayed.

\section{Results and Discussion}

\subsection{Current direction and velocity}

The pattern of sea surface current circulation varies in the waters of BoB depending on the seasonal circulation. February and August are the months that represent winter (east season) and summer (southwest 
wind season). Current circulation in $\mathrm{BoB}$ is influenced by Northeast Monsoon Current (NMC) and South Monsoon Current (SMC) [13]. The current circulation pattern generated by the plot in the current pattern mapping provides an efficient average of the results. In the east monsoon, the northeast monsoon blows bringing the ocean currents to the southwest (NMC$\mathrm{SMC}$ ).

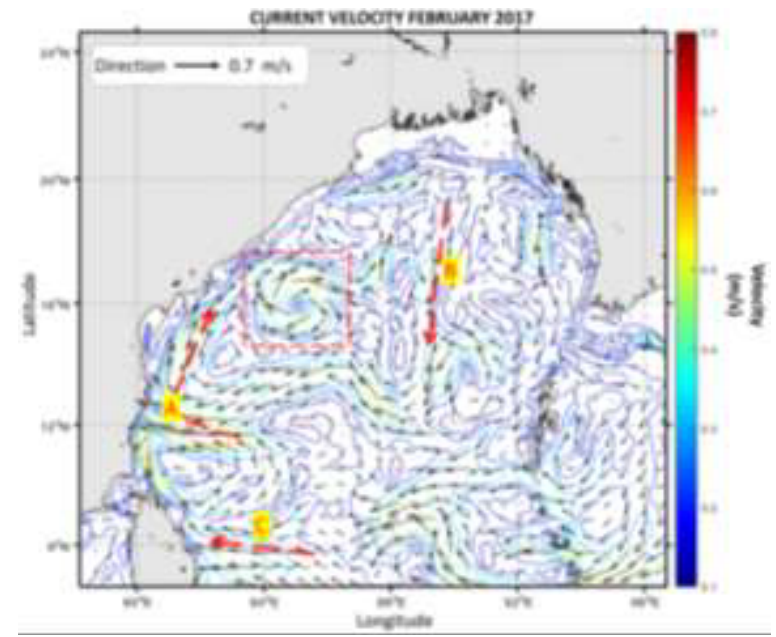

(a)

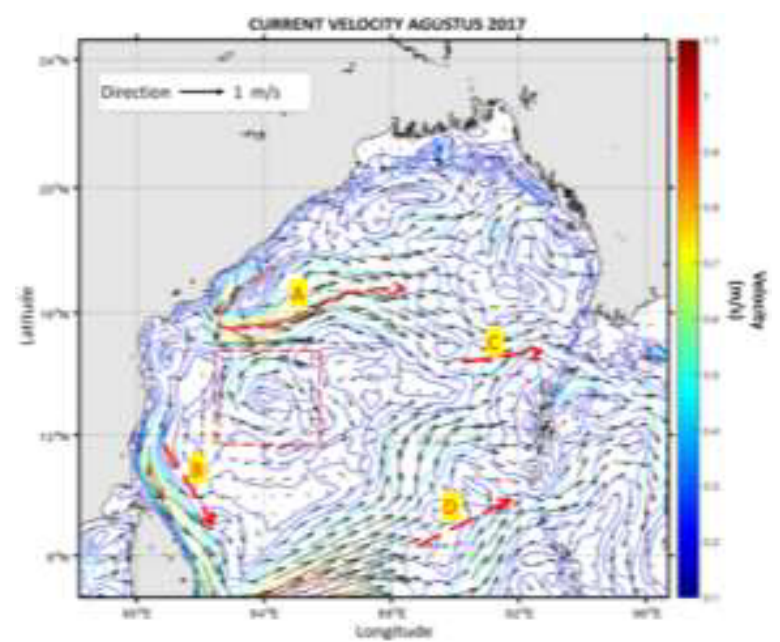

(b)

Fig. 2. (a) The direction and velocity of the current in February and (b) the direction and velocity of the current in August 2017.

Fig. 2(a) pattern of current direction and velocity in February. The current shown in February has an average velocity slightly lower than the current in August. It is due to the difference in wind pressure blowing from the northeastern mainland. An enlarged current vector as a comparison of a current direction with current velocity contours, surface geostrophic currents range from 0.4 to $0.6 \mathrm{~m} / \mathrm{s}$. A vortex (anti-cyclone) occurs in the western part of the bay at a velocity of about $0.5 \mathrm{~m} / \mathrm{s}$ at $16^{\circ} \mathrm{N}, 85^{\circ} \mathrm{E}$. In the west of the bay (condition A) at latitude $12^{\circ} \mathrm{N}$ the direction of the current turns right, the pattern is formed due to a collision with the western part of the concave mainland called WBC. The direction of the current along the west coast that interacts with the eddies flows towards the north of the bay (WBC-north) then the current is blocked by currents originating from the east so that it flows towards the middle of the bay (condition B) forming a linear direction pattern, this is influenced by the anti-slip eddies. The cyclone produces a spread towards the continental surf, resulting in a reversal of the current with an irregular flow [14]. The current deflection to the right occurs in the south of the bay (condition $\mathrm{C}$ ) where the curving current collides with the southwest boundary of the bay, namely the mainland of Sri Lanka.

Fig. 2(b) shows the current circulation, namely the direction and velocity in August. In the southwest monsoon the direction of the current reverses which is influenced by the west monsoon, where the wind blows moving the ocean currents to the northeast through the south of the bay (SMC-NMC). The current shown in August has a slightly higher velocity than the current in February, this is because the wind that blows comes from the southwest sea. Surface geostrophic currents in the west monsoon range from 0.4 to $0.8 \mathrm{~m} / \mathrm{s}$. In the west monsoon, the vortex (anti-cyclone) is observed to undergo a slight transition to the point $14^{\circ} \mathrm{N} .84^{\circ} \mathrm{E}$ west of the bay at a velocity of about $0.3 \mathrm{~m} / \mathrm{s}$. The geostrophic current pattern (condition A) has a strong contribution to bring the flow to the east with an average velocity of $0.6 \mathrm{~m} / \mathrm{s}$, the maximum current velocity of $0.8 \mathrm{~m} / \mathrm{s}$ is around the point $15^{\circ} \mathrm{N}, 83^{\circ} \mathrm{E}$. The maximum current velocity is about $0.7 \mathrm{~m} / \mathrm{s}$ (condition B) covering the southwestern part of the bay basin, where the current is heading right towards south through east Sri Lanka. This is caused by the Ekman pump and local winds around the coast. The flow of geostrophic currents from the south of about $1 \mathrm{~m} / \mathrm{s}$ carried will enter the Andaman waters (conditions $\mathrm{C}$ and $\mathrm{D}$ ).

\subsection{Distribution of sea surface temperature}

Winter identifies the average condition of SST in February with a low range which is influenced by seasonal currents. Fig. 3(a) shows the distribution of the SST in February. The lowest SST covers the northernmost waters of the bay ranging from $23^{\circ} \mathrm{C}$ $26^{\circ} \mathrm{C}$ and extends to the shallow waters of the western continental. High SST conditions cover the south of the bay which is around $27^{\circ} \mathrm{C}-29^{\circ} \mathrm{C}$. The distribution of SST seen is influenced by several seasonal current patterns that form in Figure 2.(a) It can be seen in Figure 3.(a) there is a variation in surface temperature in the western boundary area influenced by condition A on the rightward deflection of the current which brings a temperature of $27^{\circ} \mathrm{C}$ to the western boundary, the presence of an anti-cyclonic eddy produces an upwelling of $26^{\circ} \mathrm{C}$. In the northern part of the bay, it is seen that the linear current pattern forms a temperature distribution pattern where the mass of water with low temperature flows towards the center of the bay (condition B).

Fig. 3(b) shows the distribution of SST in August. Summer identifies the average condition of SST in August with a high range that dominates along the continental surf. The lowest SST around $25^{\circ} \mathrm{C}$ covers the waters of the west coast of the bay. Low SST also dominates the eastern part of the bay at the Andaman Sea land boundary averaging $27^{\circ} \mathrm{C}-28^{\circ} \mathrm{C}$. 


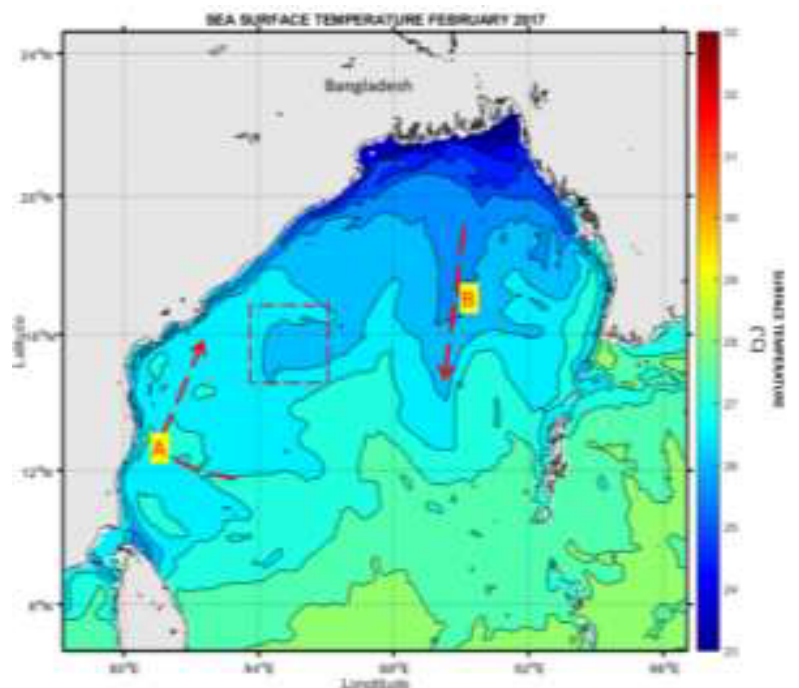

(a)

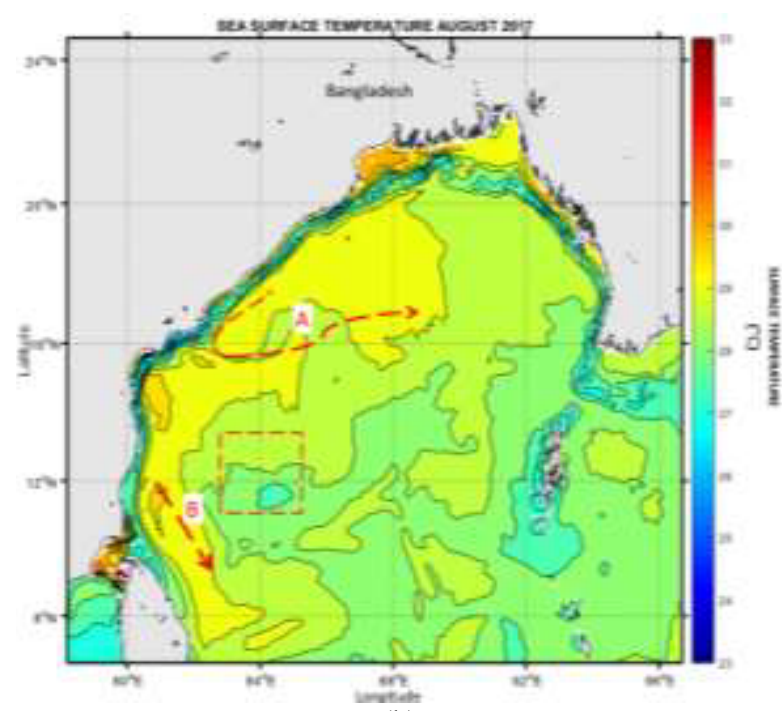

(b)

Fig. 3. (a) SST in February and (b) SST in August 2017.

In the northernmost area of the bay, the SST range is very high at $29.5^{\circ} \mathrm{C}-30^{\circ} \mathrm{C}$ due to atmospheric convection and turbidity. The high SST dominance covers the western part of the bay at an average of $29.5^{\circ} \mathrm{C}$ and interacts with anti-cyclonic eddies to produce an upwelling of $27^{\circ} \mathrm{C}$. Some of the western seasonal current patterns that form in Fig. 2(b). It provides a pattern of distribution of high surface temperatures along the western boundary. Geostrophic currents in condition A push the hot water mass to spread to the middle of the bay and in condition B the hot water mass goes to the south influenced by currents in the southwest basin.

\subsection{Sea surface salinity}

Surface salinity in February is influenced by east monsoon currents and evaporation. Fig. 4(a) shows the distribution of Sea Surface Salinity (SSS) in February. The SSS plot shows the lowest salinity distribution covering the northern and northeastern waters of the bay at 29-32.5 psu. High salinity covers the waters southwest and south of the bay (33.5-34 psu) which is maintained by high evaporation and brine mass from the oceans. The pattern of salinity distribution seen in the image plot almost follows the shape of the current pattern in February. The spread of low salinity to the center is hampered by the presence of the western circulation, it is influenced by the magnitude of the backflow in the continental surf as in conditions A and eddies. The distribution of low salinity towards the middle is seen in condition $\mathrm{B}$ and the distribution of high salinity in the southern area of the bay is 33.5-34 psu from the open water mass.

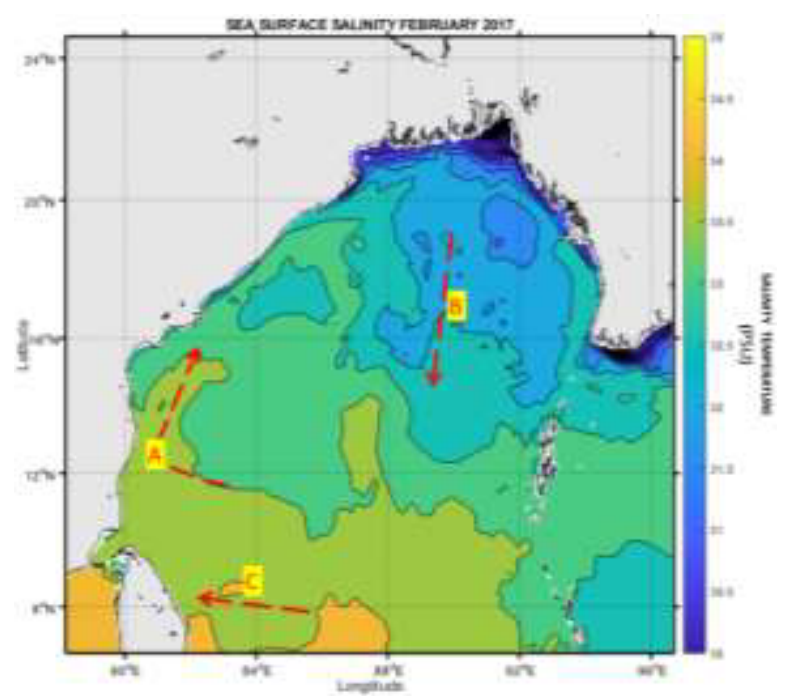

(a)

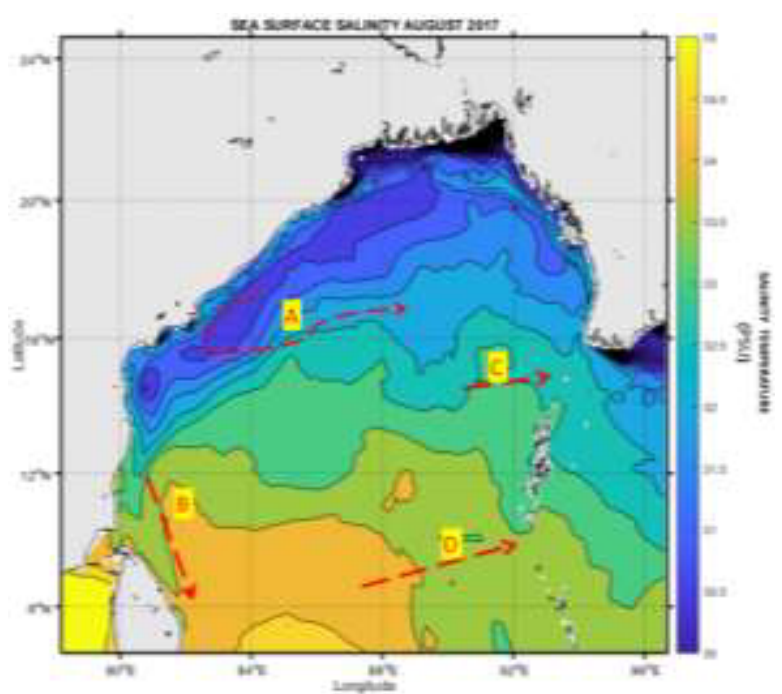

(b)

Fig. 4. (a) SSS in February and (b) SSS in August 2017.

Fig. 4(b) shows the condition of the distribution of SSS in August. In the southwest monsoon, the lowest salinity covers the north to west of the bay, which is 2031.5 psu while high salinity covers the waters of the southwest and south of the bay (33.5-34.5 psu) maintained by evaporation, where high salinity currents from the ocean enter BoB. The surface salinity distribution pattern that occurs in the plot results shows that the geostrophic current in condition A maintains the mass distribution of low salinity water dominates the 
bay. the forcing of low salinity flow to the south occurs in condition $\mathrm{B}$ by right-hand currents in the basin but the current from south to east is greater pushing the high salinity water mass of 34.5 psu. Conditions C and D show that each of the relatively high salinity water masses originating from the influence of the gulf geostrophic current flows into the Andaman Sea.

\subsection{Relationship of precipitation evaporation to SST and SSS}

and

The convention that applies to precipitation is in the form of a positive value and evaporation in the form of a negative value (-) indicating that there is an accumulation of water mass in units of $\mathrm{mm}$ water of equivalent. The variation of precipitation in each season is related to the distribution of low salinity, precipitation in August (summer) is higher than February (winter). Figure 5.(a) shows that the precipitation produced in February is very small, ranging from 1-3 mm/day, a positive value of $3.5 \mathrm{~mm}$ is only covered in the southern part of the bay. Therefore, the distribution of salinity in February is more influenced by fresh water discharge.

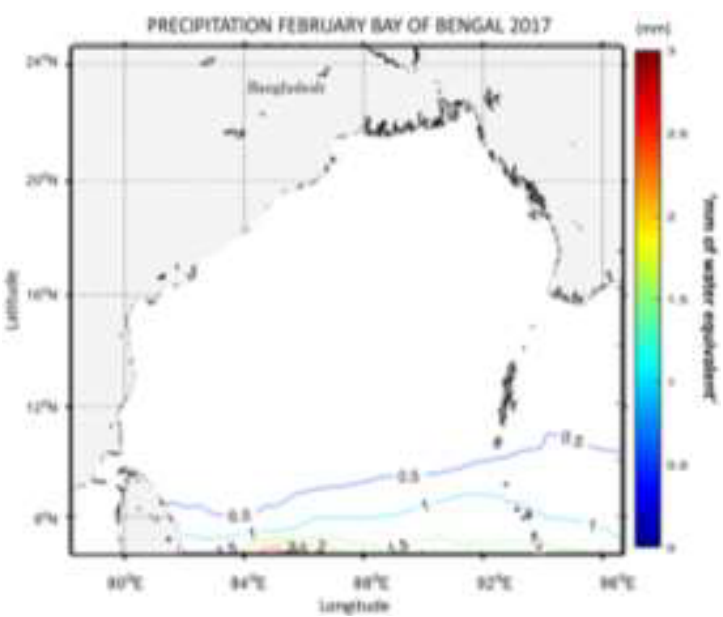

(a)

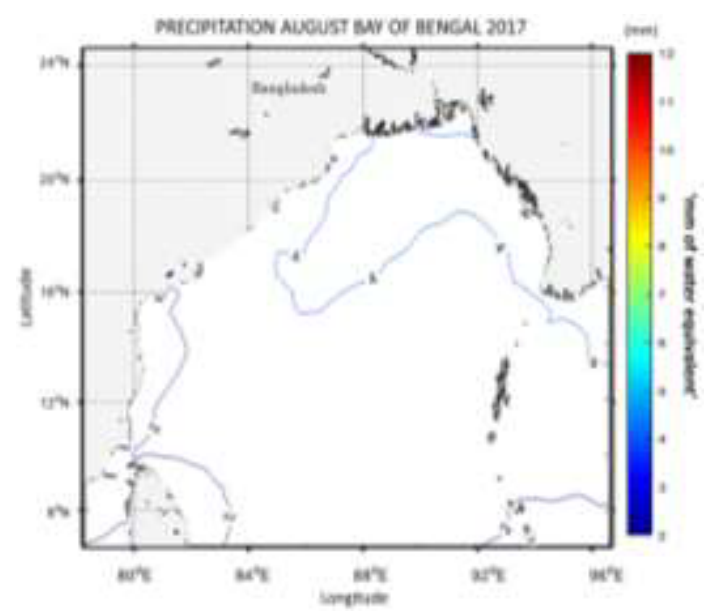

(b)

Fig. 5. (a) Precipitation in February and (b) SSS in August 2017.

In August (Fig. 5(b)), the predominance of rainfall over the bay averaged around $4 \mathrm{~mm}$, strongly supporting the maintenance of a low SSS in the north, a more positive range of precipitation values towards the mainland of the bay.

In Fig. 6(a) shows the evaporation value in February. High evaporation is indicated by increasingly negative values that dominate the center of the bay, namely -1.4 to $-1.6 \mathrm{~mm}$. The smallest evaporation is -1.8 covering the south of the bay. The value of evaporation is relatively positive to the north where the temperature is lowest. In August (Fig. 6(b)), the negative value of evaporation covers the south of $-1.6 \mathrm{~mm}$, but the negative value extends to the central bay towards the north of $-1.4 \mathrm{~mm}$.

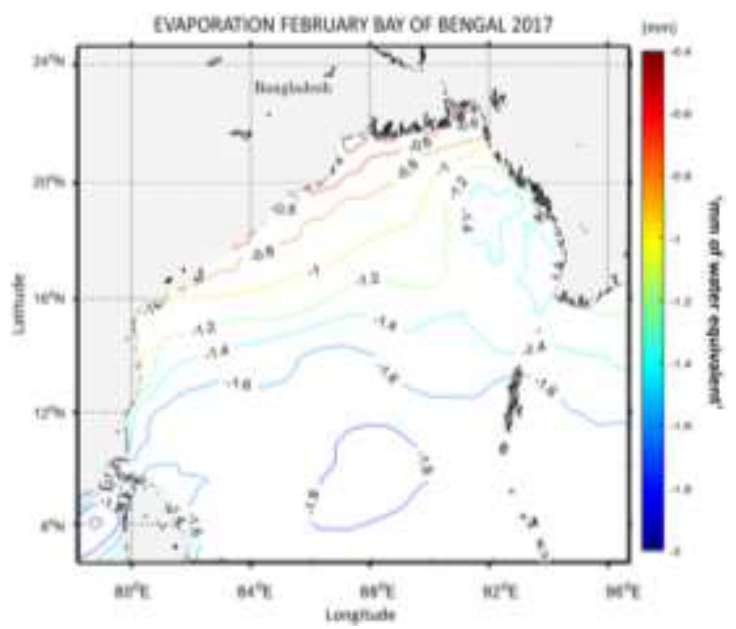

(a)

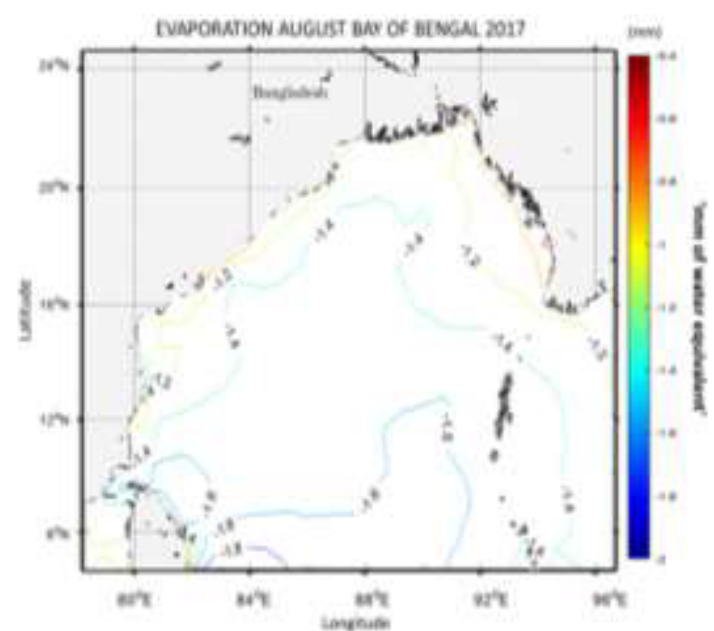

(b)

Fig. 6. (a) Evaporation in February and (b) SSS in August 2017.

In February the absolute positive value reached 4.5 mm towards the waters, while in August the positive value was $2 \mathrm{~mm}$ to $4 \mathrm{~mm}$ towards the mainland. High evaporation is supported by high SST. High SSS is supported by evaporation and low SSS is supported by high precipitation. The effect of high average rainfall values supports low SSS in the north and high evaporation supports high SSS in the south. The plot of Fig. 7 shows that the average value of the resulting precipitation exceeds the average value of evaporation. Therefore, the results of the combination of SST, SSS, precipitation and evaporation seem to have an impact on each other. 


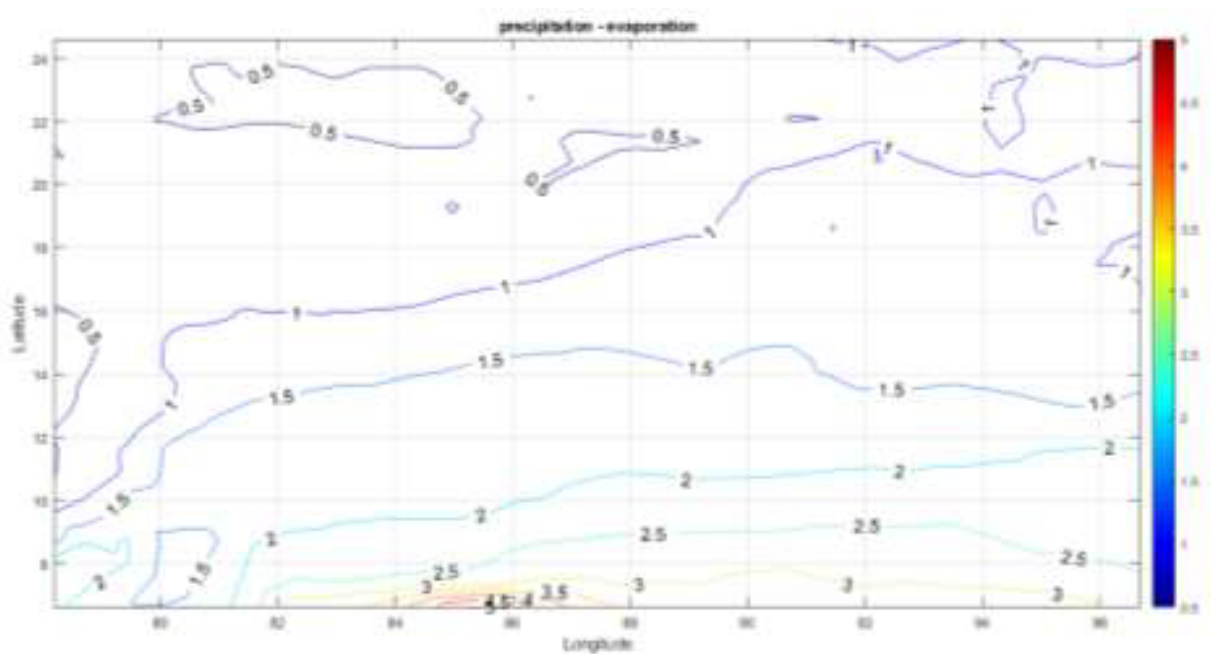

(a)

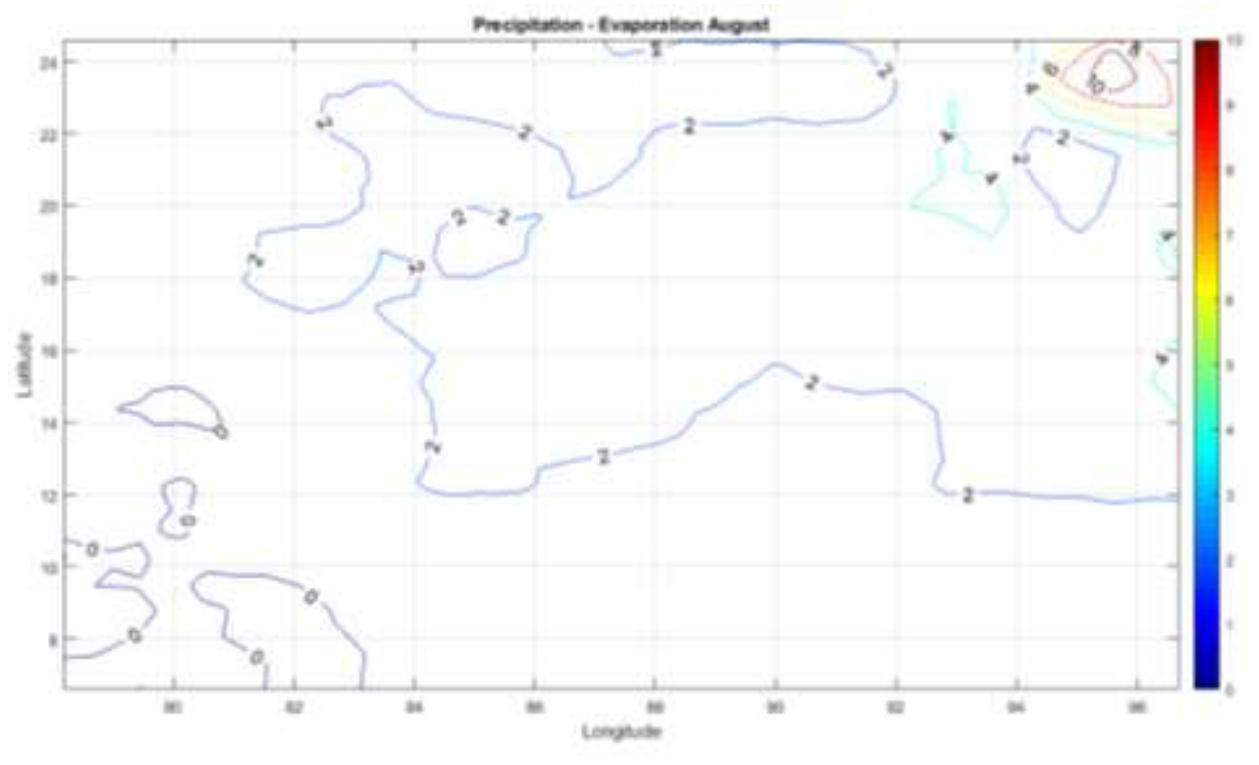

(b)

Fig. 7. Value of absolute difference between precipitation and evaporation (a) February (b) August.

\section{Conclusions}

Based on the results of the research that has been carried out, it can be concluded that in February the average sea water velocity is $0.4-0.6 \mathrm{~m} / \mathrm{s}$ forming a backflow pattern from the western boundary and in August the average sea water velocity is $0.5-0.8 \mathrm{~m} / \mathrm{s}$. In February the distribution of SST is low and SSS is relatively high following the east monsoon current pattern. In August, the SST is high and the SSS is low, following the pattern of the southwest monsoon conditions. SST and SSS variations with precipitation and evaporation conditions support each other. The negative value of evaporation is supported by high SST. High SSS is supported by negative values of evaporation and low SSS by positive values of precipitation. Marine parameter data from HYCOM at sea level gives very good calculation results. It is recommended for more further research on monsoon currents, surface temperature and surface salinity stratification in the waters of BoB for detailed information of the impact provided is useful for research in the field of Marine Science.

Acknowledgment. Authors would like to express gratitude to Universitas Syiah Kuala for financial assistance in term of 'Penelitian Terapan Unggulan Perguruan Tinggi', under contract number: 11/UN11.2/PT.01.03/DPRM /2021. The authors would like also to thank the Faculty of Marine and Fisheries for providing research support facilities. This research is carried out in the Ocean Modelling Laboratory, Department of Marine Sciences, Universitas Syiah Kuala, Indonesia.

\section{References}

1. G. S. Bhat and H. J. S. Fernando, Oceanography 29, 232 (2016)

2. L. M. Beal, V. Hormann, R. Lumpkin, and G. R. Foltz, J. Phys. Oceanogr. 43, 2008 (2013)

3. A. Chatterjee, D. Shankar, S. S. C. Shenoi, G. V. Reddy, G. S. Michael, M. Ravichandran, V. V. Gopalkrishna, E. P. Rama Rao, T. V. S. 
Udaya Bhaskar, and V. N. Sanjeevan, J. Earth Syst. Sci. 121, 559 (2012)

4. $\quad$ A. Buckley, J. M., Mingels, B., Tandon, Deep. Res. Part II Top. Stud. Oceanogr. 172, 104653 (2020)

5. J. Sree Lekha, J. M. Buckley, A. Tandon, and D. Sengupta, J. Geophys. Res. Ocean. 123, 6330 (2018)

6. Sree Lekha, J. Clim. 32, (2019)

7. Gibilisco, Remote Sens. Environ. 248, 111964 (2020)

8. K. Wyrtki, Physical Oceanography of the Southeast Asian waters (Naga Report. 1961)

9. K. Wyrtki, L. Magaard, and J. Hager, J. Geophys. Res. 81, 2641 (1976)

10. D. Ardila, Y. Haditiar, M. Ikhwan, R. Wafdan,
Muhammad, S. Sugianto, and S. Rizal, IOP Conf. Ser. Earth Environ. Sci. 348, 012063 (2019)

11. S. Rizal, Muhammad, T. Iskandar, I. Setiawan, A. Satriadi, and Radinal, Proc. AIC Syiah Kuala Univ. Banda Aceh (2011)

12. V. P. Akhil, F. Durand, M. Lengaigne, J. Vialard, M. G. Keerthi, V. V. Gopalakrishna, C. Deltel, F. Papa, and C. De Boyer Montégut, J. Geophys. Res. Ocean. 119, (2014)

13. P. N. Vinayachandran, D. Shankar, S. Vernekar, K. K. Sandeep, P. Amol, C. P. Neema, and A. Chatterjee, Geophys. Res. Lett. 40, 1777 (2013)

14. S. Mandal, S. Pramanik, S. Sil, K. S. Arunraj, and B. K. Jena, J. Coast. Res. 89, 132 (2020) 